\title{
PROTAGONISMO SÓCIO-INFORMACIONAL NA SAÚDE COLETIVA ${ }^{i}$
}

\author{
SOCIO-INFORMATIONAL PROTAGONISM IN COLLECTIVE HEALTH
}

${ }^{1}$ Doutora em Educação pela Universidade Federal da Bahia (UFBA).

E-mail: henriettefgomes@gmail.com

\section{ACESSO ABERTO}

Copyright: Esta obra está licenciada com uma Licença Creative Commons Atribuição 4.0 Internacional. $(\mathbf{c c}) \mathbf{E Y}$

Conflito de interesses: A autora declara que não há conflito de interesses.

Financiamento: Não há.

Declaração de Disponibilidade dos dados: Todos os dados relevantes estão disponíveis neste artigo.

Recebido em: 20/09/2018.

Revisado em: 01/10/2018.

Aceito em: 10/10/2018.

\section{Como citar este artigo:}

GOMES, Henriette Ferreira. Protagonismo socioinformacional na saúde coletiva. Informação em Pauta, Fortaleza, v. 3, número especial, p. 47-61, nov. 2018. DOI:

https: //doi.org/10.32810/25253468.ip.v3iEspecial.2018.39713.47-61.

\section{RESUMO}

Aborda o protagonismo sócio-informacional na saúde coletiva tratando do conceito de informação, da natureza da saúde coletiva e do potencial de ambas para a conscientização quanto à necessidade de humanização do
Henriette Ferreira Gomes ${ }^{1}$

mundo. Trata ainda do desenvolvimento do protagonismo sócio-informacional em saúde coletiva, na condição de ação mediadora, refletindo acerca das características e dimensões da mediação da mediação da informação, objetivando contribuir para o estabelecimento de articulações entre os campos da Saúde Coletiva e Ciência da Informação para a mediação consciente da informação, favorecedora do processo de apropriação da informação em saúde enquanto lastro ao desenvolvimento do protagonismo social.

Palavras-chave: Protagonismo social. Mediação da Informação. Mediação da informação em saúde coletiva.

\section{ABSTRACT}

Approach the social-informational protagonism in collective health presenting the concept of information, the nature of collective health and the potential of both to raise awareness about the need to humanize the world. It also discusses the development of socio-informational protagonism in collective health, in the condition of mediating action, reflecting on the characteristics and dimensions of mediation of information and the aiming to contribute to the establishment os articulations between the Collective Health and Information Science to the conscious mediation of information, favoring the processo of appropriation of health information as a means to the development of social protagonism.

Keywords: Social protagonism. Mediation of information. Mediation of information in Collective Health. 


\section{INTRODUÇÃO}

A concretização do protagonismo sócio-informacional na saúde coletiva convida a importantes reflexões acerca do conceito de protagonismo, do conceito de informação e a condição de conhecimento que esta última contém, da natureza da saúde coletiva e do seu potencial conscientizador da necessidade de humanização do mundo. Em outra perspectiva, observa-se que o desenvolvimento do protagonismo sócio-informacional em saúde coletiva, como em qualquer campo do conhecimento, do saber ou da cultura, se realiza por meio de atividades de mediação.

Nesse sentido, com base em estudo da literatura desses campos, apresentam-se reflexões acerca do arcabouço conceitual para compreensão do protagonismo, da relação entre a produção e disseminação da informação com o protagonismo, a base protagonista da saúde coletiva e das próprias atividades informacionais, assim como a imprescindível mediação consciente da informação em saúde coletiva.

Assim, este texto se desdobra na abordagem acerca do que vem a ser protagonismo; do desenvolvimento do protagonismo sócio-informacional em saúde coletiva; sobre a mediação da informação e suas contribuições ao protagonismo, finalizando com a tentativa de delinear as articulações necessárias ao alcance do direito coletivo à saúde, como condição humanizadora do mundo.

\section{QUE VEM A SER PROTAGONISMO?}

Ao abordar o protagonismo sócio-informacional na saúde coletiva percebe-se a necessidade de iniciar a discussão acerca do significado de protagonismo. Tomando como referência os estudos de Perrotti (2017), ressalta-se que é em Antígona de Sófocles (496-409 a.C.) que se pode observar a gênese do conceito de protagonismo.

Na obra de Sófocles, ao receber a notícia de que seus dois irmãos morreram em batalhas, sendo que um deles, por ter se colocado em campo oposto, foi alvo da decisão do rei de Tebas, Creonte, de não permitir seu sepultamento, ordenando a exposição do seu corpo ao ataque de aves de rapina, Antígona reagiu, se erguendo e indo a luta reivindicatória do sepultamento do irmão, argumentando diante do rei Creonte que sua reação se pautava nas leis dos deuses regentes da vida na pólis, para os quais o 
sepultamento é um direito de todos independente de seus atos. Mas Creonte não aceita os argumentos de Antígona, condenando-a ao sepultamento em uma caverna subterrânea, ainda com vida, desconsiderando as leis de Tebas, e, assim, colocando a esfera do privado (das suas paixões) acima da esfera pública, gerando um período de violência que passou a comprometer a vida coletiva, o compartilhamento e a relação entre os diferentes, comprometendo, enfim, o respeito à alteridade, que é a base sustentadora da vida social. Ao contrário da conduta de Creonte, Antígona representa a esfera pública que se ergue contra a extrema valorização do privado.

Desse modo, observa-se que na sua origem, o conceito de protagonismo se relaciona com a valorização da vida cidadã, na qual o outro e o diferente são respeitados e compreendidos como sujeitos ativos na constituição de todos.

Conforme Perrotti (2017), o termo protagonismo tem sido empregado em diferentes campos da ação social, em especial no âmbito das lutas por direitos de diferentes naturezas. No entanto, o autor chama atenção para certa perda do sentido originariamente concebido por Sófocles, em sua obra, onde o protagonista é o principal lutador $($ proto $=$ primeiro, principal associado à agonistes, o que luta, lutador). Nessa perspectiva, protagonismo se relaciona à conduta de resistência e combate, de enfrentamento de antagonismos (que lutam contra) que afetam a todos na sociedade.

Protagonismo implica em tomada de posição, o que coloca os protagonistas em posição de liderança na luta contra os obstáculos que representam ameaças, assumindo embates pela construção de um mundo comum. Ser protagonista significa assumir a condição de sujeito social que age com e em relação ao outro, estando este outro presente na cena da ação ou presente apenas simbolicamente.

O sujeito protagonista é aquele que age, que se ergue, que se coloca em relação ao "mundo comum". Conforme Perrotti (2017), para o protagonista, mais importante que vencer uma luta, derrotando o adversário, é a afirmação dos princípios básicos do viver junto. Para o protagonista importa reagir, lutar e superar o fazer vazio, sem significação.

$\mathrm{Na}$ mitologia grega, em razão da sua vida pouco convencional, Sísifo foi condenado pelos deuses a carregar uma pedra até o topo de uma montanha, para ali equilibrá-la, o que tornava o castigo permanente, já que ao atingir o topo, a pedra acabava por se soltar, descendo montanha abaixo. Nesse mito, identifica-se a 
representação do trabalho inútil, ao qual não há reconhecimento social, nem tampouco retorno compensatório. No entanto, Sísifo, no seu esforço de retornar com a pedra ao topo, encontra-se com sua consciência e sente sua própria força, uma força superior à do rochedo que tenta vencer, já que, apesar da dor, do cansaço, da infelicidade, ele resiste e ergue novamente a pedra em direção ao topo da montanha, tornando essa capacidade de resistir, essa força do insistir, na sua própria razão de viver. Sísifo encontra em si a essência da resistência, encontra a sua felicidade, já que dá significado ao trabalho inútil, ao castigo imposto, o que o torna no âmbito da sua consciência um forte, um ser resiliente, rebelando-se contra o destino imposto, erguendo-se, portanto, como protagonista e abandonando a posição de vítima.

Nesta linha reflexiva acerca do conceito de protagonismo, pode-se iniciar a focalização do protagonismo sócio-informacional, no qual a informação é resultante do compartilhamento do conhecimento produzido socialmente.

Conceituando informação como conhecimento em estado de compartilhamento, Gomes (2016, 2017) ressalta a natureza social da informação, fruto do processo dialógico que sustenta e subsidia a geração do conhecimento, por potencializar a capacidade humana de interpelar, de interferir, de criar e recriar o próprio conhecimento anteriormente instituído e o próprio mundo. Os sujeitos sociais se constituem e constituem o mundo no processo de socialização, no qual a interação é elemento essencial de construção de sentido, se caracterizando como um fenômeno sócio-cultural com características lingüísticas e discursivas, por meio da qual as falas produzidas pelas "vozes" são organizadas para que ocorra compreensão, debate, dissenso e consenso entre interlocutores. (BRAIT, 2001).

Vários são os dispositivos concebidos e articulados ao processo de interação, que atuam como elementos mediadores, nos desafiando a desconstruir a visão reducionista de oposição entre os homens e seus objetos, assim como a expandir a concepção de dispositivos, compreendendo-os enquanto os próprios processos, técnicas e ambientes produzidos pelo humano, que com eles estabelece uma relação dialética e produtora de sentidos.

A informação é resultante e promotora da ação de compartilhamento, situandose enquanto ação dependente da interação, por ser produzida, organizada, acessada e apropriada no processo de encontro com o outro, o que lhe dá um caráter alteritário. 0 outro que produz, o outro que organiza, disponibiliza, possibilita o acesso e uso, mas que 
também constrói e oferta dispositivos facilitadores do encontro e do debate com os outros, ampliando as possibilidades de novas interpretações.

Nesse sentido, Gomes (2016, 2017), ao compreender a informação como conhecimento em estado de compartilhamento, a está caracterizando, ao mesmo tempo, como produto gerado no esforço de colocar em comum e produto movente da ação de comunicar, já que permite o acesso ao conhecimento (que encontra-se nesse estado materializado), guardando a potência promotora de novas ações de comunicação, a partir das quais podem emergir revisões, novas perspectivas e até a geração de novos conhecimentos.

Nesta linha reflexiva, revela-se o caráter social da informação, que resulta da ação humana de colocar em comum, de compartilhamento, de busca do encontro com o outro, que a retomará em outro agir, em outra ação e reação, indicando esse movimento como germe do protagonismo. 0 agir encontra-se na centralidade do protagonismo por exigir a tomada de posição. Para Arendt (2007) o agir significa tomada de posição, de iniciativa, de imprimir movimento a algo, sinalizando que na ação o protagonismo é colocado em cena.

Arendt (2007) assinala ainda que a ação é a condição capaz de preservar o espaço político, no qual a intersubjetividade favorece o exercício da crítica, ampliando a possibilidade de interação e negociação, de articulação e acordo entre os sujeitos sociais.

Em outra perspectiva observa-se também que o agir comunicativo permite o compartilhamento social dos conhecimentos e saberes. Informação guarda, portanto, uma propriedade material, por meio da qual, a condição abstrata do conhecimento torna-se passível de ser visualizada, refletida, revisitada, no movimento recursivo que assegura o pensamento crítico sustentador da tomada de posição por parte do sujeito leitor, qualificando esse compartilhamento como uma atitude consciente da comunicação que viabiliza o olhar crítico, o debate e possivelmente, o estabelecimento do estado de consenso social, defendido por Habermas na sua teoria da ação comunicativa.

Para Habermas (1987), a interação é uma esfera do social, por meio da qual os sujeitos convivem, agem e se comunicam, buscando o caminho do entendimento e do consenso possível para as decisões em torno das coisas do mundo do sistema e do mundo da vida. Na interação se pode, por meio da intersubjetividade, reconhecer e 
questionar as pretensões de validade das manifestações, construindo o estabelecimento, sempre provisório, do que seja verdade. Mas, para que a ação comunicativa alcance efetividade é preciso assegurar socialmente que a todos seja garantido:

a) o espaço de voz, necessário aos questionamentos, argumentações e respostas às questões formuladas a partir de suas falas;

b) o exercício do debate problematizador da validade dos discursos, no combate às ideias preconcebidas, preconceitos, estigmas, enfim a tudo que limite o respeito à alteridade;

c) a expressão dos sentimentos, atitudes e desejos (subjetividades);

d) a contestação, a exigência ou permissão para que explicações sejam manifestadas em réplicas e tréplicas que estabeleçam atos reguladores da própria interação, da vida ativa, do mundo do sistema e do mundo da vida.

$\mathrm{Na}$ concepção de Habermas (1987), a ação comunicativa emerge enquanto interação entre sujeitos que agem e se expressam, capazes de estabelecer relações interpessoais, buscando a compreensão quanto às motivações da discussão em foco e a situação na qual ocorre a interação, assim como quanto aos planos de ações coordenadas pela via do entendimento.

A partir do conceito de informação de Gomes (2016, 2017), passando pelas abordagens de Arendt (2017) que ressalta o valor da ação, da tomada de posição, e de Habermas (1987) que assinala o valor social da ação comunicativa, tentou-se aqui apontar as conexões entre Protagonismo e Informação, compreendendo o protagonismo como ação de luta, do embate necessário à construção e consolidação do espaço público, realizada por sujeitos conscientes da necessária superação dos interesses privados que colocam em risco ou em situação de ameaça os interesses públicos, sujeitos que assumem a luta entre o público e o privado, em favor da pólis. Desse modo, acredita-se ter contornado o que se poderia denominar de protagonismo sócio-informacional, compreendendo-se que a luta em favor do interesse público só pode ser assumida no âmbito social, na expansão da ação coletiva, para a qual a informação é elemento central e potencializador do debate que engendra o exercício do espaço crítico, do qual emergem os sentidos e decisões. Mas, cumprindo o objetivo deste texto, a seguir se busca abordar o protagonismo sócio-informacional no contexto da saúde coletiva. 


\section{DESENVOLVIMENTO DO PROTAGONISMO SÓCIO-INFORMACIONAL EM SAÚDE COLETIVA}

Refletindo sobre o protagonismo sócio-informacional no contexto da saúde coletiva, deve-se rememorar que esta, se volta aos interesses públicos, no debate e na produção de conhecimentos e ações concretas em favor da saúde no âmbito do social, dos coletivos sociais.

A saúde coletiva representa a saúde vivida na coletividade, decorrente dos impactos das posições e decisões sócio-econômicas de uma sociedade, podendo, portanto, ser planejada, evitando o desenvolvimento e alastramento social de patologias e outros problemas que repercutam sobre a saúde da população.

Normalmente confunde-se saúde pública com saúde coletiva, ainda que exista certa diferença entre elas. A saúde pública se ocupa da prevenção de patologias ou problemas que afetam a saúde de uma população, portanto, está vinculada a políticas, ações e serviços realizados pelo estado, que visam alcançar as condições sanitárias adequadas à promoção da saúde da população.

Por seu lado, a saúde coletiva se caracteriza como movimento social em favor das condições sanitárias, que consiste da realização de estudos para identificação da realidade social, econômica e ambiental, do qual participam pesquisadores do campo da saúde articulados a outros das ciências sociais. A partir desses estudos cooperativos são produzidos resultados capazes de subsidiar o estabelecimento das políticas públicas que visam à eliminação ou controle de cenários epidêmicos.

Desse modo, verifica-se que a saúde pública é derivativa dos estudos realizados no âmbito do campo científico da saúde coletiva. A saúde pública pode e deve ser estabelecida a partir da saúde coletiva, visando o estabelecimento de políticas públicas e ações do estado voltadas a toda população.

A saúde coletiva se caracteriza como um campo científico. Conforme Paim e Almeida Filho (1999, 2000) trata-se de um campo interdisciplinar que articula pesquisadores, teorias e estudos das ciências da saúde, da administração e das ciências sociais.

Nesta diferenciação, pode-se observar a estreita ligação entre saúde coletiva e protagonismo. A própria saúde coletiva resulta da ação protagonista de pesquisadores e 
estudiosos que se articularam pela democratização da medicina, pela aproximação da medicina e com as ações da saúde voltadas ao interesse da coletividade.

Conforme Paim e Almeida Filho (1998) e Schraiber (2008), a saúde coletiva no Brasil emerge dos movimentos pela democratização do país, focalizando a necessidade de uma reforma sanitária capaz de democratizar a saúde, assegurando-a ao conjunto da população. Assim, o movimento pela saúde coletiva ergueu-se no cenário do autoritarismo, na luta pelos direitos sociais, em ações protagonistas.

Enquanto campo científico que parte do movimento social para compreendê-lo em termos de suas condições e necessidades de saúde e que se propõe ao estudo dessas condições para proposição de políticas públicas, assim como de disseminar na sociedade conhecimentos que alterem positivamente suas condições de saúde, a saúde coletiva têm no campo da Ciência da Informação um parceiro na geração de serviços e produtos que, ao mesmo tempo, possam auxiliar na obtenção das informações para análise e estudos, como também na mediação da informação em saúde que potencialize a tomada da posição protagonista por parte da sociedade, através dos movimentos sociais que lutam pela igualdade de direitos e pelo respeito à alteridade, enfim, na luta pela democratização da saúde.

Na prospecção de informações destinadas aos estudos, os ambientes públicos de informação podem colaborar, assim como no processo de disseminação, acesso, uso e apropriação social das informações produzidas pelo campo científico da saúde coletiva. Os dispositivos de mediação da informação e os mediadores da informação (profissionais da informação) são parceiros potenciais da saúde coletiva para o desenvolvimento do protagonismo sócio-informacional.

Progressivamente os sujeitos sociais entendem a informação em saúde como um direito universal e buscam obter informações que lhes possibilitem ter contato com o conhecimento especializado dessa área, para refletir e adotar condutas que imprimam qualidade às suas condições de vida. Por outro lado, os pesquisadores da saúde coletiva buscam obter informações a partir das quais possam diagnosticar e propor políticas em favor da saúde da coletividade. Essa realidade coloca os campos da Ciência da Informação e da Saúde Coletiva em articulação.

Segundo Campal García e Pastor Morán (2008), pesquisas têm indicado que o tema da saúde representa o maior interesse informacional deste século, em especial 
porque a maior parte das populações busca ir além dos diagnósticos e tenta se municiar de informações para melhor dialogar com as equipes médicas.

Em todo o mundo são realizadas atividades por profissionais e ambientes informacionais para disseminar informações especializadas e desenvolver competências em saúde, preparando os cidadãos a manejarem fontes confiáveis de informação, habilitando-os na compreensão das recomendações básicas de saúde, a exemplo de prospectos ou formulários sanitários da American Medical Association - AMA (2004), desenvolvendo suas competências para ler, entender e trabalhar com informação em saúde. (ANDRUS; ROTH, 2002).

Para a American Library Association (ALA), competência em informação se caracteriza como o conjunto de competências e habilidades ligadas ao "[...] reconhecer quando se necessita da informação e possuir a capacidade de localizar, avaliar e utilizar eficazmente a informação requerida." (AMERICAN LIBRARY ASSOCIATION, 1989, p. 1). Estendendo o conceito para a informação em saúde, teve-se um movimento inicial no contexto clínico, considerando as dificuldades de interlocução entre médicos e pacientes. Mas, em paralelo, os ambientes e profissionais da informação incorporaram o conceito na disseminação da informação em saúde, tomando como referência a Carta de Ottawa de 1986, que firmou as bases teóricas e práticas da promoção da saúde. (UNIÓN INTERNACIONAL DE PROMOCIÓN DE LA SALUD Y EDUCACIÓN PARA LA SALUD, 2007).

Diversos ambientes informacionais têm desenvolvido atividades dessa natureza, em especial bibliotecas públicas como as bibliotecas de Iowa, Denver, Toronto, Colorado, Kansas, Missouri, Nebraska, Wyoming, sempre em articulação com bibliotecas especializadas em Medicina. Destacam-se ainda bibliotecas que atuam em projetos como da National Network PF Libraries of Medicine, cujo objetivo é o de desenvolver as bases do trabalho conjunto com as bibliotecas públicas. (CAMPAL GARCÍA; PASTOR MORÀN, 2008).

Por outro lado, é importante ponderar que o desenvolvimento de competências em informação sobre saúde visa não apenas o acesso à informação, mas também o processo de apropriação da informação sobre saúde por parte dos sujeitos que, com tal domínio, poderão agir em favor a ampliação das condições de vida e na adoção de medidas e comportamentos individuais e coletivos promotores de novas atitudes e estilos de viver. Assim, o desenvolvimento de competências em informação, em 
quaisquer domínios do conhecimento, sempre se caracterizará como atividade de mediação da informação, sobre a qual também se deve refletir, visando a efetividade do processo de apropriação da informação.

\section{SOBRE A MEDIAÇÃO DA INFORMAÇÃO E SUAS CONTRIBUIÇÕES AO PROTAGONISMO}

A mediação da informação se caracteriza como uma ação ligada ao processo de construção de sentidos que emergem das interações sociais e mediações simbólicas, entre as quais a mediação linguística ocupa lugar central. Conforme Orozco Gómez (2000), a mediação é o locus de geração do sentido imanente do processo da comunicação que se dá no âmbito de determinada cultura. Por seu lado, lembrando-nos Bakhtin (1981) de que é exatamente no âmbito da cultura que os signos são construídos, em especial a partir da tomada de consciência e da capacidade do sujeito desenvolver sua compreensão com base no substrato semiótico gerado nas relações sociais, na intra e na intersubjetividade resultantes das relações interpessoais. Mas, o processo de mediação também se dá na interrelação de elementos técnicos, humanos, ambientais e semiológicos que, em articulação, possibilitam a produção e o compartilhamento do conhecimento. Todos esses elementos também atuam na mediação da informação, que segundo Gomes $(2014,2016)$ possui cinco dimensões que precisam nortear esse processo: dialógica, estética, formativa, ética e política.

A partir de seus estudos Gomes $(2014,2016)$ formulou essas cinco dimensões da mediação da informação, defendendo que articuladas e alcançadas tornam a mediação efetiva e propulsora do protagonismo social. Somente na conjunção das cinco dimensões a mediação da informação favorece o processo de apropriação da informação, sem o qual o desenvolvimento do protagonismo pode se retardar, compreendendo-se que a tomada de posição acerca de qualquer problema ou luta depende do processo de apropriação da informação, que carrega em si um importante sustentáculo do processo de conscientização, que é o domínio do conhecimento associado ao exercício da crítica, por meio do qual teoria e prática se irmanam, desvendando as particularidades da realidade local, a qual pertence o sujeito que se pretende protagonista. 
Por ser dependente das práticas de comunicação, por se ocupar da transmissão cultural, envolvendo os processos de compartilhamento por meio dos quais os sujeitos podem gerar significações, a mediação da informação envolve uma dimensão dialógica. O processo dialógico possibilita o encontro e a manifestação entre diferentes interlocutores. $\mathrm{Na}$ mediação consciente, o processo dialógico favorece o exercício da crítica e a observação mais clara das incompletudes e lacunas dos conhecimentos estabilizados.

Do exercício da crítica surge a possibilidade do desenvolvimento do autoconhecimento, que permite o alcance da consciência quanto aos limites e potencialidades, aumentando a probabilidade do desenvolvimento de estratégias bem sucedidas de superação e, consequentemente, do encontro com o prazer estético, no reconhecimento da beleza do conhecimento, da apropriação e da geração do conhecimento, o que evidencia a dimensão estética da mediação da informação.

$\mathrm{Na}$ base desse processo criador localiza-se a ação consciente da busca do autoconhecimento e da disponibilidade para o encontro com a diversidade e o respeito à alteridade, o que implica na disposição para conhecer o outro, conhecer o meio e o contexto, evidenciando a dimensão da ética da mediação da informação.

Por outro lado, considerando que a mediação da informação pode também representar uma ação de interferência, conforme assinala Almeida Júnior (2009), observam-se os riscos da relação tênue entre interferência e manipulação. Nesse sentido, Almeida Júnior $(2008,2009)$ destaca que a ação mediadora consciente acerca desses riscos, ainda que não assegure a plena eliminação deles, pode reduzi-los.

\footnotetext{
A consciência e a competência para interferir evitando a manipulação são dependentes da conduta ética associada à busca de identificação de sinais que indiquem o grau de conforto, confiança, cumplicidade e cooperação que se pode gerar na ação mediadora. (GOMES, 2016, p. 103).
}

Observando a dimensão ética da mediação da informação, o profissional que a realiza precisa estar aberto a acolher, ouvir e dialogar com o outro, o implica na sua capacidade de escuta e observação sensíveis, assim como na adoção de princípios que inibam a censura e o acesso à informação, em desrespeito à igualdade de direitos e liberdade de pensamento.

Nas atividades de formação do usuário se evidencia com maior clareza a dimensão estética, formativa e ética, que devem ser analisadas no planejamento, 
execução e avaliação da mediação da informação. No entanto, de um modo geral as atividades de mediação da informação guardam um caráter formativo pela forte relação da mediação com a estética e a ética. Em essência, toda atividade humana acaba por ter um caráter formativo porque no fazer, no movimento, na ação, em certa medida acabase por inventar ou reinventar as ações e os próprios sujeitos dessas ações.

Toda ação é motivada por experiências e se concretiza na experiência. De acordo com Larrosa (2002), a experiência é tudo que se vivência, tudo que acontece ao sujeito, tudo que o toca e o afeta, enfim, o que mobiliza o sujeito. Na experiência o sujeito se recria e recria o mundo no movimento inerente ao comportamento protagonista, ressaltando a relevância da dimensão formativa da mediação da informação.

Analisando-se dimensão formativa da mediação da informação com maior cuidado, observa-se como objetivo implícito dessa mediação o desenvolvimento do protagonismo social. 0 processo dialógico torna possível a aproximação entre agentes e dispositivos de informação, o que coloca ainda em relevo a própria condição de protagonista do mediador. Este age, constrói e interfere no meio, se caracterizando como um protagonista social. 0 mediador da informação também se constitui em sujeito da estética, da ética e da produção humanizadora do mundo, o que o coloca na condição de um agente político, cuja ação mediadora também tem, portanto, uma dimensão política. Assim, na mediação da informação torna-se fundamental a reflexão e a consciência acerca das dimensões dialógica, estética, formativa, política e ética da mediação da informação.

A despeito de qualquer tipo de experiência neste sentido, torna-se relevante observar que nesses contextos, os profissionais da informação e os ambientes informacionais para atuarem de modo qualificado no desenvolvimento do protagonismo sócio-informacional em saúde coletiva e os pesquisadores e agentes da saúde coletiva precisam do estabelecimento de ações cooperativas, considerando também as cinco dimensões da mediação nomeadas por Gomes (2014, 2016 e 2017) e segundo a autora, se alcançadas tornam mais efetiva e intensa a medição da informação com condições promissoras ao desenvolvimento do protagonismo social.

$\mathrm{Na}$ concepção, planejamento e execução das atividades de mediação da informação em saúde a compreensão e consideração do espectro conceitual e das dimensões da mediação, ampliam a possibilidade de se alcançar resultados de qualidade ao desenvolvimento do protagonismo social em favor da saúde coletiva. 


\section{CONSIDERAÇÕES FINAIS}

O protagonismo sócio-informacional na saúde coletiva significa a reação e ação consciente dos agentes de informação e de saúde, em articulação com os sujeitos sociais que têm o direito do viver com saúde. Desse modo, pode-se concluir que o protagonismo sócio-informacional em saúde coletiva se caracteriza como elemento fundante do processo democrático de construção das bases de humanização do mundo.

O efetivo desenvolvimento desse protagonismo se dá por meio das atividades de mediação consciente da informação, o que implica no conhecimento do que seja informação, da sua missão social, das dimensões da mediação e da força dessa ação também protagonista. A informação, na condição de conhecimento em estado de compartilhamento, situa-se na base da construção de todos os saberes e culturas, se caracteriza como substrato e, ao mesmo tempo, produto das partilhas que se efetivam nas relações sociais, o que a caracteriza como elemento social. Para a saúde coletiva ela é elemento que, interpretado e significado, torna possível a compreensão da realidade em saúde de uma população e de suas necessidades, como também, e de modo qualificado, indica o caminho promissor da saúde assegurada e disseminada democraticamente e em respeito à alteridade.

Experiências no campo da Ciência da Informação e das Ciências da Saúde têm sido realizadas em nível mundial, contando com as expertises desses campos, dos contextos sociais locais e sob a orientação de organizações internacionais e nacionais comprometidas com a humanização do mundo. No entanto, torna-se relevante o avanço na compreensão dos pontos de convergência entre essas especialidades, da necessária articulação e cooperação, considerando as bases conceituais, teóricas e práticas que envolvem as ações em torno da saúde coletiva e da informação, norteadas especialmente para o protagonismo social. 


\section{REFERÊNCIAS}

ALMEIDA JÚNIOR, O. F.; BORTOLIN, S.

Mediação da informação e da leitura. In: SILVA, T. E. (Org.). Interdisciplinaridade e transversalidade em Ciência da Informação. Recife: Néctar, 2008. p. 67-86.

ALMEIDA JÚNIOR, O. F. La mediación de la información y la lectura informacional. In: GARCIA MARCO, F. J. (Org.). Avances y perspectivas en sistemas de información y documentación.

Zaragoza: Universidad de Zaragoza, 2009. p. 23-28.

AMERICAN LIBRARY ASSOCIATION. Presidential Committee on Information Literacy. Final report. 1989. Disponível em: <https://bit.ly/2Sct0Js>. Acesso em: 14 ago. 2018.

AMERICAN MEDICAL ASSOCIATION. Health literacy top priority, 2004. Disponível em: <https://bit.ly/20YJv4J>. Acesso em: 14 ago. 2018.

ANDRUS, M. R.; ROTH, M. T. Health literacy: a review. Pharmacotherapy, v. 22, n. 3, p. 282-302, 2002. Disponível em: $<$ https://bit.ly/2DVA9WA $>$. Acesso em: 14 ago. 2018.

ARENDT, Hanna. A condição humana. 10. ed. Rio de Janeiro: Forense Universitária, 2007.

BAKTHIN, M. Marxismo e filosofia da linguagem. São Paulo: Hucitec, 1981.

BRAIT, B. 0 processo interacional. In: PRETI, D. (Org.). Análise de textos orais. 5. ed. São Paulo: Humanitas, cap. 9, p. 189-214, 2001.

CAMPAL GARCÍA, F.; PASTOR MORÁN, M. Informando en salud en la biblioteca pública. In: CUEVAS, A. (Coord.). Competencias en información y salud pública. Brasília, DF: Editora do Departamento de Ciência da Informação e Documentação da UnB, 2008. p. 606-617.
DAHLET, P. Dialogização enunciativa e paisagens do sujeito. In: BRAIT, B. (Org.).

Bakhtin, dialogismo e construção do sentido. Campinas: Unicamp, 1997. p. 59-87.

GOMES, H. F. A dimensão dialógica, estética, formativa e ética da mediação da informação. Inf. Inf., Londrina, v. 19, n. 2, p. 46-59, maio/ago. 2014. Disponível em: <https://bit.ly/2P0oIO5>. Acesso em: 4 set. 2018.

GOMES, H. F. Comunicação e informação: relações dúbias, complexas e intrínsecas. In: MORIGI, V.; JACKS, N.; GOLIN, C. (Org.).

Epistemologias, comunicação e informação. Porto Alegre: Sulina, p. 91-107, 2016.

GOMES, H. F. Mediação da informação e protagonismo social: relações com vida ativa e ação comunicativa à luz de Hannah Arendt e Jürgen Habermas. In: GOMES, H. F.; NOVO, H. F. Informação e protagonismo social. Salvador: EDUFBA, 2017. p. 27-44.

HABERMAS, J. Teoria de la acción comunicativa I: racionalidade de la acción y racionalización social. Madrid: Taurus, 1987.

HABERMAS, J. Teoria de la acción comunicativa II: crítica de la razón funcionalista. Madrid: Taurus, 1987.

LARROSA, J. Nietzsche \& a educação. Belo Horizonte, Fundação Biodiversitas: Autêntica, 2002.

OROZCO GOMEZ, G. La investigación en comunicación desde la perspectiva cualitativa. México: Universidade Nacional de la Plata, 2000.

PAIM, J. S.; ALMEIDA FILHO, N. A crise da saúde pública e a utopia da saúde coletiva. Salvador: Casa da Qualidade, 2000.

PAIM, J. S.; ALMEIDA FILHO, N. La crisis de la salud pública y el movimiento de la salud colectiva en Latinoamérica. Cuadernos Médico Sociales. Rosario, v. 40, n. 75, p. 530, 1999. 
PAIM, J. S.; ALMEIDA FILHO, N. Saúde coletiva: uma "nova" saúde pública ou campo aberto a novos paradigmas? Revista de Saúde Pública, São Paulo, v. 32, n. 4, p. 299316, 1998.

PERROTTI, E. Sobre informação e protagonismo cultural. In: GOMES, H. F.; NOVO, H. F. Informação e protagonismo social. Salvador: EDUFBA, 2017. p. 11-26.

PORTAL EDUCAÇÃO. Conceitos de saúde coletiva. [S.l.: s.n.], 2018. Disponível em: <https://bit.ly/2BwbOUV>. Acesso em: 21 mar. 2018.

PORTAL EDUCAÇÃO. Saúde pública. Saúde coletiva [S.l.: s.n.], 2018. Disponível em: <https://bit.ly/2BuhZbZ>. Acesso em: 21 mar. 2018.
SCHRAIBER, L. B. Saúde coletiva: um campo vivo. In: PAIM, J. Reforma sanitária brasileira: contribuição para a compreensão e crítica. Salvador: EDUFBA; Rio de Janeiro: Fiocruz, 2008. p. 9-19.

UNIÓN INTERNACIONAL DE PROMOCIÓN DE LA SALUD Y DE EDUCACIÓN PARA LA SALUD (UIPES). Consorcio Canadiense de investigación em Promoción de La Salud. Determinar el futuro de la promoción de la salud: acciones prioritarias. 2007. Disponível em: http:<https://bit.ly/2TF8Ggl>. Acesso em: 5 set. 2018. 